\title{
Paleobiolinguistics of New World Crops and the Otomanguean Language Family
}

Cecil H. Brown ${ }^{1,2}$

Author address: ${ }^{1} 1700$ Scenic Highway, \#601, Pensacola, FL, 32503-6634, USA. ${ }^{2}$ Department of Anthropology, Northern Illinois University, DeKalb, IL 60115, USA.

Email: brown.cecil@yahoo.com

Received: June 26, 2015

Volume: 6(1):189-191

Published: September 24, 2015

(C) 2015 Society of Ethnobiology

\begin{abstract}
Several studies recently published in Ethnobiology Letters treat respectively the paleobiolinguistics of chili pepper, manioc, maize, and the common bean in New World language families. This includes the Otomanguean family of Mexico, one of the oldest language groups of the hemisphere, whose parent language may have been spoken at the latest around 6500 years ago. This communication addresses the possibility that Otomanguean paleobiolinguistics should be considered tentative since languages of the grouping are not yet conclusively demonstrated to be descended from a common ancestor. This challenges the proposal that words for chili pepper, manioc, and maize were in vocabularies of languages spoken two thousand or more years before development of a village-farming way of life in the New World.
\end{abstract}

Keywords: Crop origins, Historical linguistics, Native Americans, Otomanguean, Paleobiolinguistics

My colleagues and I have published a series of papers in Ethnobiology Letters dealing with the paleobiolinguistics of New World crops, including treatments of chili pepper, manioc, maize, and the common bean (respectively, Brown et al. 2013a, b, 2014a, b). In these works, we cite reconstructions of words for crops in proto-languages (ancestral to modern language families). One of these is ProtoOtomanguean (POM) whose offspring languages are spoken in central Mexico in eight different subfamilies. The date at which POM was last spoken is 6591 $\mathrm{BP}^{1}$, making it the second oldest proto-language of the Americas (after Proto-Macro-Ge of South America dated to 7266 BP) among approximately 130 ancestral languages surveyed by us. From sources treating the historical linguistics of the Otomanguean language family (Kaufman 1990; Rensch 1976) we determine that words for chili pepper, manioc, and maize reconstruct to $\mathrm{POM}$, while a term for the common bean does not. ${ }^{2}$

I would now characterize our analysis of Otomanguean $(\mathrm{OM})$ paleobiolinguistics as tentative. I have had a growing concern that $\mathrm{OM}$ is not a demonstrated genetic group, that it should more appropriately be treated as a proposal for empirical investigation rather than as a proven language family. The possible failure of this proposal would bring into question the great antiquity of words for chili pepper, manioc, and maize in New World languages.

Vocabulary reconstructed for POM is not based on demonstrated sound correspondences holding between words of daughter languages of the proposed family. For over two-hundred years, recognition of regularly corresponding sounds has been the bedrock of the comparative method of historical linguistics. Words similar in sound and meaning from matched languages are shown to be descended from a common ancestor when comparisons are supported by regular sound correspondences. Both Rensch (1976) and Kaufman (1990) reconstruct words for POM, but these are not supported by regular sound correspondences and, consequently, their reconstructions as well as OM itself are seriously called into question. ${ }^{3}$

Despite this, most mainline historical linguists accept $\mathrm{OM}$ as a valid language family. As far as I know, I am the only student of American historical linguistics who now questions OM's demonstration. More than one factor may contribute to the broad, categorical confidence in OM genetic unity. I suspect most historical linguists simply have not looked at the supporting evidence very closely. Another factor may be the publication of Lyle Campbell's book in 1997 entitled American Indian Languages: The Historical Linguistics of Native America. In this influential work, Campbell presents a detailed internal classification of 
OM without mention of the fact that the family has not been demonstrated through use of the standard comparative method. Campbell was and still is regarded widely as conservative in his acceptance of proposed language families, so that his unqualified embracement of $\mathrm{OM}$ as a genetic group carries considerable weight.

OM subfamilies show fetching similarity including resemblances involving grammar as well as vocabulary. Some scholars point to grammatical similarities as support for genetic affinity. Contemporary $\mathrm{OM}$ languages are all spoken in a more-or-less contiguous region of central Mexico. This geographic proximity enhances the possibility that many if not all $\mathrm{OM}$ resemblances, including grammatical ones, are due to language contact and linguistic-trait diffusion taking place over millennia. Indeed, a reasonable case could be made that $\mathrm{OM}$ languages constitute a sprachbund (language diffusion area) rather than a genetic group.

OM may eventually be shown to be a valid language family. But, at present, this has not been demonstrated through strict implementation of the comparative method of historical linguistics. Until it is, we should be careful in drawing conclusions based on the assumption of $\mathrm{OM}$ genetic unity, including those of our paleobiolinguistic papers, i.e., that words for chili pepper, manioc, and maize were part of the vocabulary of a language spoken as long ago as the early Mid-Holocene, some two thousand years or more before development of a village-farming way of life in the New World.

\section{Declarations}

Permissions: None declared.

Sources of Funding: None declared.

Conflicts of Interest: None declared.

\section{References Cited}

Bartholomew, D. A. 1965. The Reconstruction of Otopamean (Mexico). Unpublished Doctoral Dissertation, Department of Linguistics, University of Chicago, Chicago, IL.

Brown, C. H., C. R. Clement, P. Epps, E. Luedeling and S. Wichmann. 2013a. The Paleobiolinguistics of Domesticated Chili Pepper (Capsicum spp.). Ethnobiology Letters 4:1-11. Doi: 10.14237/ebl.4.2013.2.

Brown, C. H., C. R. Clement, P. Epps, E. Luedeling and S. Wichmann. 2013b. The Paleobiolinguistics of
Domesticated Manioc (Manihot esculenta). Ethnobiology Letters 4:61-70. Doi: 10.14237/ebl.4.2013.5.

Brown, C. H., C. R. Clement, P. Epps, E. Luedeling and S. Wichmann. 2014a. The Paleobiolinguistics of Domesticated Maize (Zea mays L.). Ethnobiology Letters 5:52-64. Doi: 10.14237/ebl.5.2014.130.

Brown, C. H., C. R. Clement, P. Epps, E. Luedeling and S. Wichmann. 2014b. The Paleobiolinguistics of the Common Bean (Phaseolus vulgaris L.). Ethnobiology Letters 5:104-115. Doi: 10.14237/ebl.5.2014.203.

Brown, C. H., E. Luedeling, S. Wichmann and P. Epps. 2013. The Paleobiolinguistics of Domesticated Squash (Cucurbita spp.). In Explorations in Ethnobiology: The Legacy of Amadeo Rea, edited by M. Quinlan and D. Lepofsky, pp. 132-161. Society of Ethnobiology, Denton, TX.

Brown, C. H., S. Wichmann and D. Beck. 2014. Chitimacha: A Mesoamerican Language in the Lower Mississippi Valley. International Journal of American Linguistics 80:425-474.

Campbell, Lyle. 1997. American Indian Languages: The Historical Linguistics of Native America. Oxford University Press, NY.

Gudschinsky, S. C. 1959. Proto-Popotecan: A Comparative Study of Popolocan and Mixtecan. Indiana University Publication, Bloomington, IN.

Kaufman, Terrence. S. 1990. Early Otomanguean Homeland and Cultures: Some Premature Hypotheses. University of Pittsburgh Working Papers in Linguistics 1:91-136.

Nichols, Johanna. 2010. Proving Dene-Yeniseian Genealogical Relatedness. In The Dene-Yeniseian Connection, edited by J. Kari and A. Potter, pp. 299309. University of Alaska, Fairbanks, AK.

Rensch, Calvin. R. 1976. Comparative Otomanguean Phonology. Indiana University Publications, Bloomington, IN.

\section{Biosketch}

Cecil H. Brown is a linguistic anthropologist with interests in ethnobiology, historical linguistics, and Native American languages.

\section{Notes}

${ }^{1} \mathrm{BP}=$ before present.

${ }^{2}$ In another publication venue, Brown, Luedeling, Wichmann, and Epps (2013), using the approach of 
paleobiolinguistics, propose that a word for squash reconstructs to POM.

${ }^{3}$ Only two studies known to me have used the standard method of historical linguistics for comparing words of subfamilies of OM (Gudschinsky 1959, and Bartolomew 1965). These investigations have yet to be systematically evaluated. I am currently doing so through approaches developed by Brown, Wichmann, and Beck (2014), and by Nichols (2010) focusing on the extent to which observed similarities for compared languages could be due to chance. 